\title{
DUAS PERSPECTIVAS SOBRE O PROGRESSO: VOLTAIRE E ROUSSEAU
}

\author{
TWO PERSPECTIVES ON THE PROGRESS: Voltaire and Rousseau \\ DOS PERSPECTIVAS SOBRE EL PROGRESO: Voltaire y Rousseau
}

Edmilson Menezes

Professor Doutor da Universidade Federal de Sergipe.

ed.menezes@uol.com.br

\begin{abstract}
RESUMO: A consciência moderna da história encontra em Voltaire e Rousseau duas expressões decisivas para avaliar o nexo entre a vida socialmente organizada e a moral inseridas na trajetória dos homens em vista do seu aperfeiçoamento. O objetivo do trabalho é apresentar essas duas propostas tendo em vista associar a ideia de progresso ao quadro referencial da filosofia da história moderna. Através da reconstituição de determinados conceitos (no caso, o de progresso) o interesse filosófico das ideias de Voltaire e Rousseau emerge como filosofia, propriamente moderna. É verdade que temos uma filosofia difusa, que não se deixa circunscrever a um número preciso de obras e, seu estudo, especificamente neste trabalho amparado numa história comparada das "filosofias da história" (esforço em procurar uma compreensão inteligível para a sucessão dos acontecimentos no tempo, porém sem atribuir a essa sucessão um sentido), não pode ser tratado como um cotejo entre sistemas, mas como o entendimento de um discurso polêmico do qual brota as proposições filosóficas enquanto instrumentos espirituais servindo a intento bem preciso: a história torna-se matéria de reflexão filosófica.
\end{abstract}

PALAVRAS-CHAVE: Voltaire. Rousseau. Progresso. História.

ABSTRACT: The modern awareness of History finds in Voltaire and Rousseau two decisive expressions to assess the nexus between the socially organized life and the moral inserted in the path of men in view of their improvement. The objective of the work is to present these two proposals in order to associate the idea of progress to the referential frame of the philosophy of modern History. Through reconstituting of certain concepts (in this case, the one of progress) the philosophical interest of Voltaire and Rousseau's ideas emerges as philosophy, strictly modern. It is true that we have a diffuse philosophy, which do not allows to circumscribe to a precise number of works and their study, specifically in this work supported by a comparative history of "philosophies of history" (effort to seek an intelligible understanding for the succession of events in time, but not attributing to this succession a sense), it cannot be treated as a comparison between systems, but as the understanding of a controversial speech which sprouts the philosophical propositions as spiritual tools serving the very precise purpose: the History becomes matter of philosophical reflection.

KEYWORDS: Voltaire. Rousseau. Progress. History.

RESUMEN: La consciencia moderna de la historia encuentra en Voltaire y Rousseau dos expresiones decisivas para evaluar el nexo entre la vida socialmente organizada y la moral inseridas en la trayectoria de los hombres en vista de su perfeccionamiento. El objetivo de la investigación es presentar esas dos propuestas llevando en cuenta asociar la idea de progreso al cuadro referencial de la filosofía de la historia moderna. A través de la reconstitución de determinados conceptos (en el caso, el de progreso) el interés filosófico de las ideas de Voltaire y Rousseau emerge como filosofía, propiamente moderna. Es verdad que tenemos una filosofía difusa, que no se deja circunscribir a un número preciso de obras y, su estudio, específicamente en esta investigación amparada en una historia comparada de las "filosofías de la historia" (esfuerzo en procurar una comprensión inteligible para la sucesión de los sucesos en el tiempo, pero sin atribuir a esa sucesión un sentido), no puede ser tratado como un cotejo entre sistemas, pero como el entendimiento de un discurso polémico de lo cual brota las proposiciones filosóficas mientras instrumentos espirituales sirviendo a intento bien preciso: la historia se vuelve materia de reflexión filosófica.

PALABRAS CLAVE: Voltaire. Rousseau. Progreso. Historia.

Artigo recebido em setembro de 2015

Aprovado em novembro de 2015

Cad. Pes., São Luís, v. 22, n. Especial, set./dez. 2015 


\section{1 | INTRODUÇÃO}

O tema do progresso está ligado a uma tomada de consciência da realidade humana como constituindo uma entidade autônoma na perspectiva de um desenvolvimento temporal. Ele compreende alguns traços bastante definidos: o progresso é um processo necessário, contínuo, linear, cumulativo, irreversível e ilimitado. O presente não deve ser julgado em si mesmo e por si mesmo, como se formasse um absoluto, nem em referência a uma ordem transcendental. $\mathrm{O}$ presente é concebido como um momento que é objeto de ponderação em relação a estados anteriores e a estados futuros; admite-se que houve progresso quando essa sucessão temporal corresponde a um momento voltado a um aditamento de poder e de riqueza dentro do conjunto da realidade humana. Mas, o que significa, na realidade, a passagem do inferior para o superior? Com efeito, a resposta à questão reside na constatação de que a ideia de progresso é ambivalente. Primeiro, ela implica um objetivo ou, pelo menos, uma direção; segundo, tal finalidade implica um juízo de valor. Quais, então, os critérios e valores em que deve assentar a noção de progresso? Detendo-nos, de forma mais demorada, no estudo da elaboração do que a história da filosofia estabeleceu como conceito de progresso, encontraremos duas proposições intimamente relacionadas, apesar de serem distinguíveis. Aqui intervém a distinção entre progresso científico e técnico e progresso moral. Aquele, diz da lenta, cumulativa e gradual melhoria do conhecimento, o tipo de conhecimento incorporado nas artes e ciências, nas múltiplas maneiras que o homem tem para lidar com os problemas apresentados pela natureza ou pelo esforço intenso do ser humano para conviver em grupo. Constatamos, na história do pensamento, uma convicção raramente interrompida de que a própria essência ou natureza do conhecimento progride, melhora e torna-se cada vez mais perfeita. Quanto ao progresso moral, este se localiza em torno da condição moral e espiritual do homem na terra, sua felicidade, sua independência nos tormentos da natureza vez maior perfeição da natureza humana.

A consciência moderna da história encontra em Voltaire e Rousseau duas expressões decisivas para avaliar o nexo entre a vida socialmente organizada e a moral, inseridas na trajetória dos homens em vista do seu aperfeiçoamento. O objetivo e da sociedade e, sobretudo, sua serenidade e sua tranquilidade. Progredir moralmente é avançar no empreendimento resultante da ação de nossas virtudes espirituais e morais, levando assim a uma cada do trabalho é apresentar essas duas propostas tendo em vista associar a ideia de progresso ao quadro referencial da filosofia da história moderna. Através da reconstituição de determinados conceitos (no caso, o de progresso) o interesse filosófico das ideias de Voltaire e Rousseau emerge como filosofia, propriamente moderna. É verdade que temos uma filosofia difusa, que não se deixa circunscrever a um número preciso de obras e, seu estudo, especificamente neste trabalho amparado numa história comparada das "filosofias da história" (esforço em procurar uma compreensão inteligível para a sucessão dos acontecimentos no tempo, porém sem atribuir a essa sucessão um sentido), não pode ser tratado como um cotejo entre sistemas, mas como o entendimento de um discurso polêmico do qual brota as proposições filosóficas enquanto instrumentos espirituais, servindo a intento bem preciso: a história torna-se matéria de reflexão filosófica.

\section{2 | A IDEIA DE PROGRESSO: APROXIMAÇÕES}

De acordo com Jacques Le Goff, "a ideia explícita de progresso desenvolve-se entre o nascimento da imprensa no século XV e a Revolução Francesa” (1984, p. 346), isto é, desenvolve-se como ideia moderna: "Engajar-se no caminho do Progresso será, pois, para os Modernos, lançarse numa marcha a diante sem limites determinados" (TAGUIEFF, 2004, p. 78). A confiança no 
no progresso, durante muito tempo, assegurou aos modernos a indefectível certeza num sentido para a história. No entanto, pode-se dizer que até o início do século XVII os obstáculos a uma teoria do progresso estavam presentes.

Se o progresso científico foi, desde a Antiguidade, percebido (mesmo que timidamente), o progresso moral foi alvo de suspeitas, que se intensificam no século XVII. Para Le Goff (1984, p. 348) "a noção de progresso foi, na segunda metade do século XVII bloqueada pelo jansenismo e por Pascal." Essa afirmativa merece exatidão: quando aparece no debate filosófico a ideia de que o progresso científico arrastava consigo o progresso político ou moral, o consenso em torno do avanço atingido pela humanidade não recebe o assentimento geral. Na verdade, o Seiscentos já vislumbrava uma associação importante, que será notabilizada pelo século XVIII: "A ideia de progresso, de desenvolvimento, me parece ser", diz Guizot (1875, p. 15) "a ideia fundamental contida sob o nome civilização." De imediato, a palavra civilização evoca uma produção crescente de recursos e bem-estar na sociedade, assim como uma distribuição mais equitativa, entre os indivíduos, desses recursos e desse bem-estar. A precisão aqui estabelecida é de suma importância: por um lado, o progresso é sinônimo de desenvolvimento e, por outro, é entendido a partir da igualdade de condições. Dessa forma, o progresso passa a ser vislumbrado a partir de um ponto de vista moral, ou seja, passa também a ser concebido como promessa de uma vida menos penosa, fruto de um processo contínuo de abolição de limites tradicionalmente definidores da condição humana. Neste sentido, é preciso estabelecer parâmetros e limites para as diversas ciências capazes de atestar o progresso. De acordo com o autor dos Pensamentos, a história, a geografia, a jurisprudência, a teologia e o estudo das línguas pertencem ao número das ciências que "dependem da memória e são puramente históricas." Elas têm como princípio "o fato puro e simples ou a instituição divina ou humana." Sobre seus assuntos "só a autoridade pode iluminar-nos" e delas "pode-se ter um conhecimento total ao qual não seja possível acrescentar nada." Outras ciências, como a geometria, a aritmética, a música, a física, a medicina, a arquitetura, "dependem do raciocínio" e têm por objetivo "a pesquisa e a descoberta de verdades ocultas." As matérias dessas ciências "desembocam nos sentidos e no raciocínio." Aqui "a autoridade é inútil", e só a razão pode conhecer; aqui o espírito encontra liberdade para estender as suas capacidades "e suas invenções podem ser sem fim e sem interrupção." Trata-se, na situação presente, "de dar coragem àqueles tímidos que não ousam inventar nada em física e de confundir a insolência daqueles temerários que produzem novidades em teologia" (PASCAL, 1963, p. 230)1. Consequência: aperfeiçoamento, crescimento, progresso caracterizam só as ciências do segundo grupo. Cabe ao homem honesto encontrar, na história, apenas motivo para preencher sua memória com elementos leves e de distração. Se ele busca a expansão de sua capacidade intelectiva, não deve fiar-se na história, pois, pela marca indelével da heterogeneidade, ela não consegue atender aos parâmetros dedutivos da conquista do verdadeiro e da consequente expansão do espírito.

Não há maior solidez na ciência dos fatos ou dos acontecimentos históricos. Quanto dela se pode produzir exatamente nas histórias? Não podemos julgar por aqueles fatos dos quais temos um conhecimento particular, quando são escritos por outros. Qual o meio, então, para distinguir os verdadeiros dos falsos e os certos dos incertos? Pode-se bem saber que, em geral, todo historiador mente." (NICOLE, 1701, p. 30)².

\footnotetext{
${ }^{1}$ Sobre Pascal, ver: Béguin (1964); Sellier (1970).

${ }^{1}$ A fórmula é, sem dúvida, inspirada em Agostinho: "Nós [...] não devemos crer obrigatoriamente em tudo o que contém a história das nações, pois, frequentemente, os próprios historiadores se contradizem entre eles [...] porém nós ajuntamos fé, se o quisermos, a tudo o que não se opõe aos livros nos quais, e disso estamos certos, é preciso crer." (AGOSTINHO, 1841).
} 
Para o pensamento ilustrado, no entanto, o tema do progresso é aquele de um crescimento revestido de valor, atestado pelo aumento de uma variável por meio da qual podemos constatar os estados sucessivos do passado ao presente; o salto para frente já realizado autoriza a esperança de uma continuação, no futuro, da tendência que se manifestou no curso das idades precedentes. É forçoso dizer que essa capacidade para a continuidade está ligada à ideia de que qualquer ideal, estabelecido daqui para frente, precisaria estar bem determinado, ou como uma herança do passado, ou como uma expectativa. Optando-se pelo segundo aspecto, tem-se, em vez de uma procura atrás de nós dos tempos felizes, que não podemos ressuscitar, uma espera voltada para o fim de nossa estrada. E aqui intervém, com toda sua força, a ideia de progresso. Civilizar-se é pensar os diversos progressos da humanidade: a ciência desenvolvia-se incontestavelmente e propunha um novo tipo de conhecimento; não menos certo era o progresso material; o progresso social se elaborava; mais recente era o progresso político; podia-se mesmo falar num progresso religioso. Todos esses progressos levam o pensamento à seguinte conclusão: "A certeza de que o presente era mais esclarecido que as épocas anteriores deveria apressar a nossa marcha [...] O progresso é a lei do mundo das almas" (HAZARD, 1974, p. 209). Irradiando, enfim, todas as manifestações da inteligência, a razão empírica agia. Não era inata: formava-se, fortalecia-se, aperfeiçoava-se, de algum modo, a si própria. Lessing, por exemplo, dava uma decisiva contribuição para a ideia de progresso, ao transferir para a história da espécie a marcha evolutiva dos indivíduos, e interpretando como um lento devir a respectiva educação:

Toda educação tem um alvo para o gênero humano, assim como para o indivíduo! Quando se educa alguém, é para nele formar alguma coisa. [...] e virá certamente aquela era de perfeição na qual o homem, à medida que seu espírito se convença mais da aproximação de um futuro sempre melhor, não terá, no entanto, mais necessidade de perguntar a esse futuro os móveis de sua ação. (LESSING , 1897, § 82 e 85)

Todos esses dados reunidos conduziam à convicção de que se valia mais que os antepassados. Haveria melhores costumes que outrora, mais urbanidade, mais luzes, mais humanidade.

Aquele que quiser calcular os malefícios ligados à administração viciosa será obrigado a fazer história do gênero humano. De tudo isto resulta que, se os homens se equivocam em física, mais ainda em moral, e que somos abandonados à ignorância e à infelicidade numa vida que, tudo bem calculado, não possui três anos de sensações agradáveis. $O$ quê! Respondera-nos um homem em sua rotina. Acaso estaríamos melhores nos tempos dos Godos, dos Hunos, dos Vândalos, dos Francos e do grande cisma do Ocidente? Respondo que estaríamos muito mal. Digo que os homens que estão hoje à frente dos governos são muito mais instruídos do que aqueles de outrora, e é vergonhoso o fato da sociedade não ter se aperfeiçoado na mesma proporção das luzes adquiridas. Digo que essas luzes não passam ainda de um crepúsculo. Nós saímos de uma noite profunda, e aguardamos o grande dia. (VOLTAIRE, 1994, p. 1054).

O assenhorear-se do fato de que o homem é chamado a viver numa estrutura cuja marca é a civilidade, pressupõe um julgamento favorável concernente ao estado presente das coisas, excelente ao estado anterior. A certeza dessa vantagem afirma o triunfo do estado civilizado. A consciência do progresso manifesta-se, de fato, como consciência em movimento, que afirma a continuidade do movimento, sem ser, com isso, capaz de prever seu fim. O homem sente-se responsável por essa progressão; ele é seu autor, e dela reivindica o mérito - o que pressupõe a autonomia da realidade humana em relação a uma predestinação transcendente. A humanidade forma um vasto conjunto segundo a dimensão temporal; seu futuro lhe pertence e define sua identidade: "a natureza tem necessidade de uma série talvez incalculável de gerações, na qual cada uma transmite às seguintes suas 
luzes, para conduzir finalmente o desenvolvimento de seus gérmens na espécie humana até o nível perfeitamente conforme à sua destinação" (KANT, 1991, $2^{a}$ Proposição). Na verdade, em cada espírito individual a humanidade ascende à consciência de si, capaz de retrospecção e de prospecção; é esse movimento, centrado no presente, que permite definir o sentido da marcha e torna-o objeto de um julgamento do progresso.

Todavia, a filosofia do século XVIII não se caracteriza somente pelo otimismo, mas também pelo apreço do paradoxo, e com ele, a incômoda e inevitável questão: é a civilização, enquanto genuíno fruto do progresso, realmente um processo ininterrupto, com o qual a humanidade se teria comprometido? Ou poder-se-ia pensar a civilização como um artifício frágil, pois não se trata do estado natural dos homens? Em meio aos homens civilizados, encontramos ainda a escravidão, a tirania e a ignorância. Do que devemos concluir que a civilização não constitui uma unanimidade intransponível e incriticável, nem o progresso um tema aceito sem o desvio da controvérsia.

\section{3 | ROUSSEAU CRITICA A SINCERIDADE MASCARADA}

O cuidado que os séculos XVI e XVII têm em apresentar distinções sutis e refinadas quanto à dissimulação ou a arte de bem viver em sociedade não consegue desviar-se da questão que se instala paralelamente ao seu uso: como a dissimulação civilizada pode engendrar qualquer valor moral? Se a civilidade é tão somente a expressão exterior de certa polidez, se é apenas uma imitação artificial, os bons modos podem ser percebidos como uma arte enganadora, imitando virtudes ausentes, como indica o Cardeal de Metz,

boa parte de nossa felicidade devemos à sociedade civil, mas somente o homem possui o uso da palavra, pois, entre os animais, ele detém exclusivamente o gosto pelo útil e pelo lesivo, pela honestidade e pela desonestidade. De sorte que, para ele, não é suficiente que haja do que produzir seus sentimentos e suas afecções corporais, é preciso também que possa expressar os pensamentos de sua alma, suas opiniões, seus desejos, seus medos e esperanças, é para esse fim que a palavra nos é dada. (GONDI, 1887, p. 173).

Entretanto, aquele gosto pelo danoso e pela fraude leva a virtude da palavra a ser alterada, falsificada para distorcer a visão das coisas

se pelas mesmas palavras que significam estima, benevolência, amizade devemos entender o contrário; se os termos de cortesia, com os quais prometemos que faremos o conveniente e aos quais adequamos nossas pretensões, possuem um sentido reservado e não sei mais que evasões mentais contrárias, que garantias podemos nós tomar? (GONDI, 1887, p. 173).

Saber enganar delicadamente passou a compor certa "science du temps", uma adequada "sabedoria" à la mode, cujo agente principal especializa-se em ser prudente (Nequitia disciplina) e em ser dono de uma malícia instruída e disciplinada, em outras palavras, o hipócrita:

Eles [os hipócritas] agem como o veneno quando entorpecem os sentimentos pelas doçuras, enquanto sua maldade vai secretamente às entranhas e busca as partes mais nobres. Eles nos fazem mal com suas palavras; eles nos dão cicuta numa taça de rubis e esmeraldas; eles nos sufocam sob rosas e pedras preciosas; eles nos matam com espadas douradas; sic inventum est aliquando quomodo aurum non ametur. Eis como o desregramento dos nossos costumes corrompe o uso de todas as coisas. (GONDI, 1887, pp. 175-176). 
Conclusão: "Desconfiemos, portanto, do exterior" (GONDI, 1887, p. 182). Reduzidas a aparências superficiais, a polidez e a civilidade deixam, no interior, em profundidade, o campo propício aos seus contrários: a malignidade, a violência, a maledicência. "A polidez", constata La Bruyère (1993, p. 138) no final do XVII, "nem sempre inspira a bondade, a equidade, a complacência, a gratidão; delas apresenta ao menos as aparências, e faz parecer o homem, externamente, como deveria ser internamente." Com um pouco de virtude, de capacidade e de boa conduta, pode-se ser insuportável. As maneiras que se negligenciam como coisas menores são, frequentemente, o que faz com que os homens decidam sobre o bem ou o mal de alguém. Uma leve atenção sobre o gesto doce e polido previne contra o mau julgamento. Não é preciso quase nada para ser tomado como orgulhoso, incivil, desprezível, abusado; é preciso ainda menos para ser estimado como o contrário de tudo isso. A instabilidade civilizada passa a ser, então, alvo de uma investigação filosófica que pedirá contas à civilização do seu negativo ${ }^{3}$. A nova expressão critica a civilização porque ela pode reduzir-se a outros sentimentos que não os desejados para o convívio entre os homens. Ela por si só não passa de espaço privilegiado para a arte da imitação, "é a paródia estética das exigências éticas da razão" (STAROBINSKI, 2001, p. 31). Civilizando-se, os homens aprenderam a conciliar seus interesses particulares com o interesse comum, aprenderam que, por esse acordo, cada um tira mais da sociedade do que nela pode pôr. Contudo, esse plano comporta também o seu enigma: a arte de prescindir das virtudes que ele imita. Há a civilização, mas há, também, a sua máscara.

Rousseau pensa ser inaceitável essa "sinceridade mascarada", já que ela se traduz numa incompatibilidade radical entre o que se anuncia e o que se sente; em outras palavras, o filósofo despreza a máscara por ser ela filha dileta da hipocrisia - o sinal, par excelence, da civilização:

nela cultivamos a ideia de que, para tornar-se homem de bem, é adequado e proveitoso começar por ser hipócrita, e que a falsidade é caminho acertado para se chegar à virtude. $\mathrm{E}$ mais, que os vícios são enfeitados com a polidez e, dessa forma, não são contagiosos como o seriam, apresentando-se de frente, com rusticidade; que a arte de penetrar os homens fez igual progresso àquela de disfarçar-se; que estamos convencidos de não se dever contar com eles, a menos que lhes agrademos ou que lhes sejamos úteis; que se sabe avaliar as ilusórias ofertas da polidez, o que, sem embargo, significa que, quando dois homens se cumprimentam, do fundo do coração um diz ao outro: eu vos trato como um idiota e zombo de vós, e o outro responde-lhe também do fundo de seu coração: sei que mentis cinicamente, mas vos retribuo com a maior boa vontade. (ROUSSEAU, 1996, p. 60).

Eis, portanto, a ideia de fragilidade da civilização e de seu caráter paradoxal: ela deseja a aproximação entre os homens, embora cultive o que verdadeiramente os separa, ou seja, a opacidade, a mentira, a hipocrisia, a máscara. A despeito de a noção de vida civilizada ter sido gestada já no século XVI, é Rousseau que cria, propriamente, nos tempos modernos, o problema da civilização, assim como inventará o conflito entre l'homme e le citoyen ${ }^{4}$. Na verdade, o termo civilização só aparece, enquanto termo constituído, em 1756 e os dois discursos de Rousseau são anteriores a essa data (1750 e 1755). Entretanto, se o termo não se encontra na obra do filósofo, o processo ali está registrado, e tal processo corresponde exatamente ao sentido ativo do termo civilização, quer dizer, à ação coletiva e original que faz a humanidade sair da barbárie. A posição inovadora do Genebrino permite a abertura de um novo flanco na tão controvertida e plural filosofia das Luzes; dessa fresta nasce uma questão nevrálgica: a progressão contínua e indubitável é necessariamente um progresso?

\footnotetext{
${ }_{4}^{4}$ Tal conflito é apresentado e trabalhado em: Goldschmidt (1980, p. 94). Para um excelente tratamento do tema da civilização em Rousseau, consultar: Vincenti (2005).
} 
Grosso modo, a civilização que a representação científica tem em vista pode-se denominar criativa - ao passo que aquela ressaltada no Discurso sobre as ciências e as artes nos leva, imediatamente, a crer que não falamos do mesmo fenômeno; a civilização que Rousseau analisa pode-se chamar parasitária ${ }^{5}$. Este não visa a civilização enquanto suscitada pelos gênios criadores, mas enquanto degradada e corrompida pelos seus usuários. No entanto, o filósofo não se refere somente àqueles atirados à escória; são tocados, especialmente, os subservientes "às opiniões do seu século" para dele recolher as recompensas (ROUSSEAU, 1996, p. 25). São eles que fazem nascer e proliferar uma funesta desigualdade entre os homens pelo privilégio dos talentos e pelo aviltamento das virtudes. Aqui encontramos o efeito mais evidente do caráter essencialmente científico da civilização. Ele antagoniza vício e virtude somente para privilegiar o primeiro; e, dessa forma, pergunta-se mais sobre talento do que sobre probidade, mais sobre utilidade do que elegância e correção da forma. As recompensas são multiplicadas em favor do engenho para rebaixar a virtude. As ciências e as artes fortalecem e dão o tom da civilização, tornando os homens civilizados "escravos felizes" que amam o gesto delicado e fino, a doçura de caráter e a urbanidade dos costumes, em uma palavra: "a aparência de todas as virtudes sem que delas se possua nenhuma" (ROUSSEAU, 1996, p. 7). A honestidade e a virtude dão lugar aos talentos e o gosto é substituído pelo fausto. As boas ações são ofuscadas pelos belos e eloquentes discursos. Difícil conceber indivíduos que direcionam suas preocupações a coisas sem nenhuma importância como passíveis de possuir alguma virtude, e, caso tivessem, "faltar-lhes-ia intrepidez para exercê-la", pois seus vícios não permitiriam a ação a partir da forma virtuosa. Em suma, suas virtudes são apenas vícios encobertos.

Um progresso científico é colocado na dianteira como alavanca impulsionadora dos caminhos humanos, enquanto um progresso moral não passaria de uma consequência do primeiro. A unidade da nossa civilização repousaria inteiramente numa cultura científica solidificada pelas conquistas modernas no campo técnico e no domínio da natureza, e cuja interferência moral é absolutamente dispensável. Dessa forma, a unidade do progresso é colocada em xeque quando a pergunta pela felicidade é, comparativamente, posta ao lado do avanço das ciências e das artes. Na verdade, considerando os autores que valorizam o desenvolvimento do conhecimento científico, o progresso moral foi sempre assimilado com estrangeiro, algumas vezes inassimilável, frente ao progresso geral. O que os teóricos do progresso chamam de acrescentamento moral da humanidade deveria, com efeito, constituir seu coroamento, como realização final. Sua irredutibilidade presuntiva aos outros gêneros de progresso (científico, técnico, jurídico, etc.) não deixou de constituir a base de um grande argumento contra a evidência do progresso. Face à soma dos progressos realizados, logo que observada a ausência do progresso moral, a interrogação insistente reaparece: qual, então, o mérito desses progressos se os mesmos não conseguem, em consequência, tornar a humanidade moralmente melhor?

\section{4 | VOLTAIRE: civilização e progresso}

O pensamento voltairiano fornecerá outra interpretação para o progresso moral e seu liame com as conquistas da ciência. O século XVIII abre as vias da inteligência histórica ao reconhecer a diferença entre passado e presente, traço que lhe confere a consciência de que os homens do presente se diferenciam dos anteriores, pois se encontram numa época privilegiada. Ele identifica-se com a civilização, as ciências, a filosofia, e possui um particular gosto pelo caminho percorrido

${ }^{5}$ As expressões são de Goldschmidt (1980, p. 112). 
percorrido pelos povos e pelos ensinamentos daí retirados: o uso da história narrativa cede lugar a um espírito investigativo e crítico vis-à-vis ao modo de se interpretar a história. Não há dúvidas de que se vive num século especial, num século filosófico e propenso à educação; e essa confiança no presente - momento mais esclarecido do que as épocas antecessoras -, deveria apressar a marcha dos homens e lhes propor uma nova forma de pensar. A história traz os exemplos a serem seguidos ou rejeitados, é o árbitro que garante a certeza de que se é melhor do que os antigos. Os séculos os mais grosseiros e mais ignorantes foram sempre fonte de vícios e de corrupção.

Apesar de ter presenciado o nascimento de grandes gênios, a ausência, em épocas anteriores, de muitos elementos da formação do espírito livre e autônomo impedia que se estendesse a liberdade e o conhecimento para um maior número de mentes. Deixemos o homem sem cultura, ignorante e, consequentemente, insensível aos deveres, e ele se tornará supersticioso e servil; sua mente, desprovida de conteúdos, se tornará presa fácil para o engodo. A matéria que ali deve ser depositada é o conjunto de conhecimentos e valores amealhados pelos homens em sua história. No entanto, se esse conteúdo assume uma feição monolítica e intransigente, ele não desempenhará, de forma adequada, sua função, porque deixou de servir também ao presente. Para o pensamento setecentista, a história deve traduzir o progresso. Sendo assim, a capacidade para o progresso fornece a base para uma crença mínima num plano de evolução humana em conjunto, de um avanço geral rumo ao melhor; ao mesmo tempo, o progresso é medido pelo quantum de civilidade e instrução somadas por um povo em sua trajetória.

Os espíritos se esclareceram no século de Luís XIV, e no seguinte, muito mais do que em todos os séculos precedentes. Vimos quanto as artes e as letras se aperfeiçoaram [...]. Os homens mais instruídos, nos últimos tempos, sentiram a necessidade de amenizar nossas leis, como, enfim, amenizaram-se os costumes. É preciso dizer que nesses costumes houve, na mesma proporção, tanta ferocidade como leviandade e ignorância nos espíritos, até os bons dias de Luís XIV." (VOLTAIRE, 1957, p. 1557).

Os "novos tempos" veem-se a si próprios a partir da óptica de uma "sensibilidade espiritual", ativada ao menor sinal de retorno a valores do passado como escravidão e violência, superstição e sombra. O presente compreende a si próprio como atualidade da época mais recente e deve encarar, daqui por diante, como uma espécie de renovação incessante, a ruptura que esses novos tempos levaram a cabo com o passado. O núcleo fundamental da história passa a ser a obra e não a figura espetacular de um grande rei, o crescimento econômico, intelectual e social de um país e não suas conquistas territoriais. O historiador não deve preocupar-se com detalhes frívolos, que funcionam como perfumaria na construção das imagens dos grandes personagens. Estes, aliás, devem-se apresentar, no registro histórico, balizados pelo critério político da contribuição para a felicidade e o bem-estar dos povos. Encher a memória com detalhes vulgares em nada contribui para a sua consciência política. Pelo contrário, eles a dissipam e a distraem.

Escrevendo um ensaio sobre os costumes, Voltaire lhes dá um novo sentido, tornando-os objeto da atenção filosófica e histórica. A partir dos costumes é possível "penetrar" o espírito dos homens e deslocar as lentes da História do seu epifenômeno para o enfoque do gênero humano propriamente dito:

As sociedades conseguem, com o tempo, retificar suas ideias; os homens aprendem a pensar. Pensou- se menos em recolher uma enorme multidão de fatos eclipsando-se uns aos outros, do que agrupar os principais e os mais reconhecidos para servirem de guia ao leitor, e fazê-lo julgar, por si mesmo, a extinção, o renascimento e os progressos do espírito humano, reconhecendo os povos pelos próprios usos desses povos. (VOLTAIRE, 1963, p. 906). 
Ao contrário, aquele que se dedica à seara histórica deve elevar-se acima do contingente, do singular absoluto. Não deve ser sua intenção retratar o individual, o que é produto do acidente, mas o "espírito dos tempos" e o "espírito das nações." Voltaire não se prende à simples sequência de fatos, mas se volta para o progresso da cultura e para sua organização interna em seus diversos elementos.

$\mathrm{Na}$ corte se realiza, em vastas dimensões, o mais rápido dos consumos, o dos serviços pessoais, que são consumidos ao serem produzidos. Sob essa denominação, é preciso compreender o serviço dos militares, dos criados, dos funcionários úteis ou inúteis, dos funcionários da administração, da justiça dos eclesiásticos, magistrados, atores, músicos, bufões da sociedade... Os próprios produtos materiais parecem mais expostos à destruição do que em outros ambientes. As iguarias finas, as fazendas magníficas, as obras de moda vêm, à porfia, mergulhar nas cortes; nada, ou quase nada, sai delas ${ }^{6}$. E, no entanto, "o supérfluo é coisa muito necessária" (VOLTAIRE, 1963, p. 203). De fato, a filosofia de Voltaire assume o supérfluo e cria uma justificativa filosófica para ele. O homem moderno está consciente de que o produto da riqueza corrompia os costumes; que a corrupção dos costumes causava a ruína dos impérios; mas, não era menos verdade que esse produto do gosto embelezava os dias; e que o homem, sem as alegrias da beleza, era o mais desgraçado e triste dos animais. Tudo se passa como se, agora, essa fosse uma marca distintiva do mundano, como lembra os versos de Voltaire: "Eu amo o luxo, e mesmo a preguiça, / Todos os prazeres, as artes de toda espécie / A limpeza, o gosto, os ornamentos: / Todo homem honesto é possuidor de tais sentimentos" (VOLTAIRE, 1963, p. 203). Aquele que renega o apreço pelos prazeres não diz, de todo, a verdade. A civilização criou novas necessidades e, com elas, novos prazeres aos quais não se pode resistir, mesmo deles não usufruindo diretamente, pois "Neste mundo, tudo serve ao luxo e aos prazeres" (VOLTAIRE, 1963, p. 203). Sem dúvida, o luxo marca uma linha divisória entre os que possuem e aqueles que querem possuir. As diferenças não apagam o desejo contínuo de se aproximar daquela fronteira: "Este esplendor, esta pompa mundana, / De um reino feliz é a marca evidente./ O rico nasceu para muito gastar;/ O pobre foi feito para muito poupar" (VOLTAIRE, 1995, p. 208).

A grande penúria do estado primitivo do mundo, e o triunfo do estado civilizado, encontrá-los-emos muito mais cedo em O mundano (1737) de Voltaire. Os nossos pais eram pobres: há algum mérito em ser pobre? A sua vida era frugal e fácil, mais por ignorância do que por virtude. Nossos bons antepassados viviam na inocência: não conheciam nem o meu nem o teu. Como poderiam ter conhecido? Eles não tinham nada! A idade do ouro não passava da idade do ferro. Que não nos fale de Ítaca, demasiado gabada por Fénelon 7 por nada teríamos concordado em lá viver. Ilusão essa beatitude do casal primevo, sem a ciência do bem e do mal:

Meu caro Adão, meu guloso, meu bom pai/ Que fazias nos recantos do Éden?/ Engendravas este parvo gênero humano?/ Acariciavas Eva, minha mãe?/ Confessa que ambos tínheis/ Unhas um tanto compridas, sujas e negras?/ Os cabelos deveras mal arrumados,/ A tez escura, a pele seca, curtida./ Sem limpeza, o mais feliz amor / Não é amor, é necessidade vergonhosa./ Fartos em breve de tão bela aventura,/ Sob um castanheiro ceiam galantemente/ Com água, milho e bolotas;/ Finda a refeição, eles dormem na pedra dura:/ Eis o estado de natureza pura. (VOLTAIRE, 1995, p. 204).

\footnotetext{
${ }^{6}$ Sobre a reação burguesa contra o espírito do século XVIII aristocratic, ver: Say (1953); Starobinski (1994).

${ }^{7}$ Os poetas, quando querem encantar (charmer) a imaginação dos homens, conduzem estes para longe das grandes cidades, e fazem com que esqueçam o luxo deste século; eles os levam à idade de ouro [...] Eu prefiro cem vezes mais a pobre Ítaca de Ulisses, que uma cidade reluzente de uma tão odiosa magnificência." (FÉNELON, 1997, p. 1195).
} 
Longe da solidão idílica fruímos dos produtos que o mundo inteiro nos remete; as belas artes disputam entre si a atenção dos olhos; passeamos em belos jardins; a limpeza, o gosto e os ornamentos nos aprazem; habitamos belas casas; são nossos os banhos perfumados, as mesas elegantemente servidas, os pratos refinados e saborosos, o champanhe, as ceias íntimas. Pede Voltaire o reconhecimento não tartufo de tudo isso e que cada um de nós possa atestar: "Do Paraíso encontramos o lugar:/ O paraíso terrestre encontra-se onde eu estou" (VOLTAIRE, 1995, p. 206, grifo do autor). O mundo abriga a vida dos costumes e, nele vivendo, o homem não possui mais simplesmente o código regulador das violências extremas. O controle do cotidiano, cujas violências possuem uma natureza mais localizada, pede, no mundo cortês, outros programas e com eles, outros perfis.

Com efeito, tudo nos envia ao homem. Recorrer a Deus, como um refúgio para ampliar uma "zona misteriosa" que envolve a humanidade, em nada contribui para o progresso das gentes, pois essa atitude coloca o homem no mais absoluto opróbrio e inviabiliza a história enquanto campo privilegiado para o conhecimento do próprio homem e da responsabilidade que esse deve assumir para o seu aperfeiçoamento. Em nada é útil mostrar o homem apenas sob uma luz odiosa, malvado e infeliz. Voltaire ousa tomar partido da humanidade. O homem não é um enigma, ele parece estar em lugar apropriado no reino da natureza:

\begin{abstract}
superior aos animais, aos quais se aparenta pelos órgãos, inferior a outros seres, aos quais se assemelha provavelmente pelo pensamento. Como tudo o que se vê, está mesclado de bem e mal, de prazer e de dor. Está munido de paixões para agir e de razão para o governo das ações. Se perfeito fosse, seria Deus, e as pretendidas contrariedades a que chamais contradições são os ingredientes necessários que entram na composição do homem, que é aquilo que deve ser. (VOLTAIRE, 1995, p. 104).
\end{abstract}

Tomar partido da humanidade significa investigá-la em seus limites e em suas possibilidades: o homem sofre, enfrenta o mal, cai, destrói, mente, engana mas, ao mesmo tempo, pode conhecer o bem, constrói, soergue-se e a seu companheiro, descobre a verdade e maravilha-se com ela. A grande contribuição da filosofia é recompor, o quanto lhe é possível, a trajetória da humanidade e identificar seus erros e acertos para trabalhar em vista do bem da sociedade e contribuir para a educação do espírito humano. Uma história percebida en philosophe debruça-se na compreensão das necessidades da humanidade em busca de seu progresso. Sua utilidade reside em nos permitir comparar os costumes do nosso país àqueles de povos estrangeiros e de tempos passados, a fim de melhor avaliar os nossos em sua justa importância. A unidade da história, enquanto atividade propriamente humana, é identificada e perseguida a partir de um trabalho de aperfeiçoamento que atinge a todos indistintamente. Partindo desses moldes, a filosofia torna-se prática e a humanidade passa a ser seu objeto de interesse real: "A humanidade é o princípio de todos os meus pensamentos", diz Voltaire (1955, p. 68). A filosofia encontra-se com o homem concreto e temporal: "Eu examino o homem" (VOLTAIRE, 1955, p. 69). Afirma o Patriarca de Ferney.

Com efeito, não importa de quais materiais é composto, é necessário nele identificar os vícios e as virtudes. Eis o ponto importante no que diz respeito ao homem, e eu não falo levando em consideração uma sociedade singular vivendo sob determinadas leis, mas refiro-me a todo o gênero humano: a vós, senhor, que deveis reinar, ao lenhador de vossas florestas, ao doutor chinês e ao selvagem da América. (VOLTAIRE, 1955, p. 69).

O que se quer mostrar é que esta humanidade engloba conceitualmente uma ideia de espírito humano (aberto à singularidade própria à espécie) e não mais uma humanidade enquanto um todo que caminha de forma homogênea para um destino arquitetada em estreita e inamovível sintonia 
com o plano providencial. Escrever a história do gênero humano, concebê-la como história profana, coloca em relevo a universalidade do conceito de homem enquanto um ser capaz de progredir. A ausência de uma diretriz sobrenatural preestabelecida permite lançar a humanidade numa história que é processual e tributária da responsabilidade dela própria. Ela, a humanidade, não é mais um peregrino que sabe de antemão que o sucesso ou insucesso de sua empreitada encontra-se escrito no projeto redentor, no qual não tem nenhuma participação. A sucessão das gerações marca um esforço de aperfeiçoamento da humanidade e, justamente, esse esforço, é o guia que orienta a possibilidade do caminhar para o melhor. A morte e a renovação de cada um da espécie não são vistas como uma marca do sofrimento atroz imposto ao homem pelo pecado, mas são tidas como marca natural incontornável e da qual temos que nos servir para o aprimoramento da geração presente e das vindouras: a história é o grande laboratório de onde se extrai as experiências com as quais devemos aprender. Sem a renovação da espécie não haveria história possível; semelhante característica impõe à história o traço singular da humanização.

O manto sóbrio que envolvia o destino da humanidade é retirado pelas ideias iluministas, e Voltaire, dentre elas, responsabiliza-se por uma ideia de história capaz de juntar os homens pelo que neles há de mais evidente quanto à sua organização e à sua cultura: o filósofo concebe a história a partir de

uma ideia geral das nações que habitam e que devastam a Terra. Encontrareis por entre essa imensidão somente aquilo que merece ser por vós conhecido: o espírito, os costumes, os usos das principais nações; tudo isso apoiado sobre fatos que não podem ser ignorados. (VOLTAIRE, 1963, p. 165).

Ao tornar-se uma história concebida pelos seus atores, isto é, pelos próprios homens, põe-se a serviço do esclarecimento. Quando a história santa é abandonada, é o gênero humano que assume o papel principal de sua própria conduta. Isso lhe concede o estatuto da autonomia conquistada a cada passo em que a humanidade se reconhece em luta constante contra o obscurantismo, justamente, naqueles grandes momentos nos quais a cultura suplantou a ignorância. Basta que cada homem faça um retorno sobre si e sobre a experiência das gerações passadas e medite sobre os princípios morais que lhe são inatos, para que sua razão encontre nele próprio uma legalidade universal dominando todas as legislações particulares. Essa razão lhe fará ver a unidade da humanidade na experiência moral e na experiência histórica: portanto, há um fundo comum no desenvolvimento da humanidade. Uma história filosófica da humanidade não necessita de um redentor estranho ao próprio gênero: a humanidade é a responsável por si mesma, por seus períodos de avanço e de retrocesso. Em Voltaire, é dessa tensão que se alimenta a ideia de história do progresso dos homens. 


\section{5 | CONSIDERAÇÕES FINAIS}

À medida em que se distanciam das áridas condições de sua vida primitiva, os homens adquirem novas necessidades e multiplicam, ao mesmo tempo, os motivos de agitação e de inquietude. O trajeto dessa evolução, compreendidos aí a linguagem, o trabalho e as formas de organização em sociedade, não desconheceu, de igual modo, as guerras, as religiões (o plural, por si só, já nos diz das implicações que isso acarreta) e toda uma sorte de conflitos daí oriundos. Nesse exato ponto, um progresso científico e social reclama um correspondente moral e, assim sendo, o reclame acaba por atribuir-lhe limites. Constatar o progresso não é tudo, é preciso nele compreender um valor moral. Se deixarmos de lado o ponto de vista moral para nos referirmos unicamente ao ponto de vista científico, o progresso só aparecerá como uma variação, uma multiplicação de efeitos: ele diversifica os costumes e as leis, ele aumenta ao infinito os conhecimentos sobre a natureza e produz e aperfeiçoa as artes. Podemos admiti-lo sob essa forma, sem crer que ele constitua um aperfeiçoamento verdadeiro e profundo ou entendendo que ele arrasta consigo conquistas espirituais que interferem positivamente na ação humana. A tensão entre progresso moral e progresso científico assume um interesse filosófico somente na modernidade e, dessa tensão, estrutura-se uma das bases da reflexão ilustrada sobre a história. O interesse foi, minimamente, recompor uma dessas investidas a partir da crise espiritual em torno do progresso, porque dela nasce um conjunto de conceitos (civilização, história, progresso moral) que nos permitem retraçar a configuração da filosofia da história e, por meio dela, entender seus pilares de interpretação. Neste sentido, é possível afirmar certa ambiguidade contida no conceito setecentista de progresso, aqui analisado através do confronto entre Voltaire e Rousseau, levando em consideração o nexo história e progresso. 


\section{Referências}

AGOSTINHO. Civitas Dei XXI, 6. In: - Opera Omnia (Patrologiae Latinae, 41). Paris: J-P Migne, 1841.

BÉGUIN, A. Pascal par lui-même. Paris: Seuil, 1964.

FÉNELON. Réflexions sur la grammaire, la rhétorique, la poétique et l'histoire ou mémoire sur les travaux de l' Académie Française. (Lettre à l'Académie) In:

Oeuvres. Paris: Gallimard, 1997. v. 2. (Bibliothèque de la Pléiade).

GOLDSCHMIDT, V. Le problème de la civilisation chez Rousseau. In: Manuscrito, n. 2, abril de 1980.

GONDI, Paul de (Cardinal de Retz). Discours sur I'hypocrisie. In: Oeuvres. Paris: Librairie Hachette, 1887. t. IX. (Collection des Grands Ecrivains de la France).

GUIZOT, F. Histoire de la civilisation en Europe depuis la chute de l'Empire romain jusqu'à la Revolution Française. Paris: Didier, 1875.

HAZARD, Paul. O pensamento europeu no século XVIII (2). Tradução Carlos G. Babo. Lisboa: Presença, 1974.

KANT, I. Idee zu einer allgemeinen geschichte in weltbürgerlicher absicht (2a Proposição). In: WEISCHEDEL, Wilhelm (Ed.). Werkausgabe. Frankfurt am Main: Suhrkamp Verlag, 1991.

LA BRUYĖRE, J. Les caractères ou les moeurs de ce siècle (1687). Paris: Bookking International, 1993.

LE GOFF, J. Progresso. In: Enciclopédia Einaudi. Tradução Irene Ferreira. Lisboa: Casa da Moeda, 1984. (Memória e História, v. 1).

LESSING, G. E. Die erziehung des menschengeschlechts (§ 82 e 85). In: Sämtliche Schriften

(Band XIII). Leipzig: Göschen'scheVerlagshandlung, 1897.

MENEZES, E. Moral e vida civilizada: notas sobre a avaliação moderna de seus nexos. In: KANT, I. Começo conjectural da história. Tradução Edmilson Menezes. São Paulo: UNESP, 2010.
NICOLE, P. Faiblesse de l'homme (1671). In: Essais de morale. Paris: G. Desprez, 1701.

PASCAL, B. Préface sur le traité du vide. In: Oeuvres complètes. Paris: Éditions Du Seuil, 1963.

ROUSSEAU, J-J. Écrits politiques. In: . Oeuvres completes. Paris: Gallimard, 1996. t. III. (Bibliothèque de la Pléiade).

SAY, J-B. Textes choisis. Paris: Dalloz, 1953.

SELLIER, Ph. Pascal et saint Augustin. Paris: Albin Michel, 1970. cap. 5.

STAROBINSKI, J. A invenção da liberdade 1700-1789. Tradução Fulvia Moretto. São Paulo: Edunesp, 1994. cap. 1.

STAROBINSKI, J. As máscaras da civilização. Tradução Maria Lúcia Machado. São Paulo: Companhia das Letras, 2001.

TAGUIEFF, P-A. Le sens du progrès. Paris: Flammarion, 2004.

VINCENTI, Luc. La civilisation chez Rousseau et Kant. In: BINOCHE, B. (Org.). Les équivoques de la civilisation. Seyssel: Champ Vallon, 2005.

VOLTAIRE. Des singularités de la nature (1768). In: - Dictionnaire de la pensée de Voltaire par luimême. Belgique: Éditions Complexe, 1994. . Essai sur les moeurs. Paris: Garnier, 1963. . Lettre de Voltaire à Frédéric, Prince Royal de Prusse, octobre 1737. In: . Lettres choisies de Voltaire. Paris: Garnier Frères, 1955.

Mélanges. Paris: Gallimard, 1995. (Bibliothèque de la Pléiade).

Précis du siècle de Louis XV (XLII). In: Oeuvres historiques. Paris: Gallimard, 1957.

(Bibliothèque de la Pléiade). 